\title{
Repeatability of agronomic characters in Brachiaria brizantha cultivars ${ }^{1}$
}

\author{
Janaina Azevedo Martuscello², Thiago Gomes dos Santos Braz ${ }^{3}$, Liana Jank ${ }^{4}$, Daniel de \\ Noronha Figueiredo Vieira da Cunha ${ }^{2}$, Madson Williame Melo Souza ${ }^{3}$, Gerlane Ferreira de \\ Brito $^{5}$, Leandro Pereira de Oliveira ${ }^{5}$
}

\author{
${ }^{1}$ Financially supported by CNPq \\ ${ }^{2}$ Universidade Federal de São João Del Rei/MG, Brazil. \\ ${ }^{3}$ Universidade Federal de Viçosa/MG, Brazil. \\ ${ }^{4}$ Embrapa Gado de Corte/MS, Brazil. \\ ${ }^{5}$ Universidade Federal de Alagoas - Campus Arapiraca/AL, Brazil.
}

\begin{abstract}
This experiment was carried out with the objectives of determining repeatability coefficients, the number of harvests necessary to increase accuracy and the genotypic stability of yield characteristics in Brachiaria brizantha cultivars in the northeast region of Brazil in the period from July 2009 to March 2011. The experimental design used was completely randomized with three treatments (Brachiaria brizantha var. Marandu, Xaraés and Piatã) and three replications. Each plot was harvested seven times: five in the rainy season and two in the dry season. Immediately after each harvest, the forage was weighed and dried to obtain total, stem, leaf and dead dry matter yields. For the estimation of the repeatability coefficient, analysis of variance, principal components (correlation and covariance matrices) and structural analyses were used. The repeatability coefficients (r) obtained by the different methods, for all characteristics evaluated, varied from 0.009 to 0.837 . The estimates of the repeatability coefficients obtained for all characteristics evaluated by the method of analyses of variance were almost always lower than those obtained by the other methods. By the principal components method (based on the covariance matrix), the estimates were always higher than those from other methods. Considering that levels of 80 or $90 \%$ confidence are satisfactory in the evaluation of the relative superiority of the cultivars for all the evaluated characteristics, with the exception of dead matter yield, the seven harvests are sufficient for the choice of the best cultivar to be used in the northeast region of Brazil.
\end{abstract}

Key Words: forage breeding, forage production, selection

\section{Introduction}

The Brazilian "agreste" is a region that goes from the state of Bahia to Piauí, characterized as a transition zone between the "Zona da Mata" and the "Sertão", with annual rainfall between 650 and 1000 millimeters (Aguiar et al., 1981). Due to the irregular distribution of the rainfall in the region, forage options for use in animal production systems are scarce, making research in selection of cultivars adapted to the region necessary.

Due to the need for increasing productivity so that agribusiness may be economically viable and competitive, pasture management should be seen as a priority source of income increase; however, no management may be adequate without previous adoption of the right forage. In this context, the farmer in the state of Alagoas, northeastern Brazil, in general, does not have a variety of cultivars to avoid monoculture and increase animal production. Thus, studies aiming at selecting specific forages adapted to this region could help the farmer.
During the process of selection of new cultivars to be used in a specific pasture environment, it is important to be sure about the genetic superiority of the selected cultivar. The analysis of successive measures of a determined agronomic characteristic is important in the selection of perennial forages, since it is expected that the initial superiority or inferiority of a cultivar in relation to others will be maintained along successive measurements. So, the measure of consistency in the position of the classification of individuals along successive measurements of a determined character is called repeatability (Turner \& Young, 1969). According to Falconer \& Mackay (1996) and Cruz et al. (2004), repeatability may be defined as the correlation between successive measures obtained in the same individual, with evaluations performed along time or space.

When a characteristic presents high repeatability, there is an indication that the increase in the number of repeated measures will result in low gain in accuracy. On the other hand, when repeatability presents low values, a large 
number of measures are necessary to reach a satisfactory determination level.

Thus, the objective with this study was to estimate the repeatability coefficients by four methods and the number of harvests necessary to increase accuracy and genotypic stability of yield characteristics in B. brizantha cultivars grown in the agreste of Alagoas state, a typical region of the northeast of Brazil.

\section{Material and Methods}

The experiment was held in the experimental area of Universidade Federal de Alagoas/Campus Arapiraca, during the period from July 2009 to March 2011. The environment where the study was conducted was Arapiraca, a district situated in the region of sub-humid agreste (Northeast region of Brazil), where the climate, according to the climatic classification of Köppen, is of As' type with a dry season in the Summer and rainfall in the Autumn/Winter. The soil of the experimental area, classified as an oxisol (red-yellow latosol) (EMBRAPA, 1999) was collected and evaluated for its chemical characteristics. Soils samples were collected from the layer 0 to $20 \mathrm{~cm}$ and sent to analyses in a specialized laboratory. The soil presented the following results: $\mathrm{pH}\left(\mathrm{H}_{2} \mathrm{O}\right)-5.4 ; \mathrm{Ca}^{+2}-4.7 \mathrm{cmol}_{\mathrm{c}} / \mathrm{dm}^{3} ; \mathrm{Mg}^{+2}-$ $2.2 \mathrm{cmol}_{\mathrm{c}} / \mathrm{dm}^{3} ; \mathrm{Al}^{+3}-0.0 \mathrm{cmol}_{\mathrm{c}} / \mathrm{dm}^{3} ; \mathrm{H}+\mathrm{Al}-4 \mathrm{cmol}_{\mathrm{c}} / \mathrm{dm}^{3}$; saturated bases $-7.23 \mathrm{cmol}_{\mathrm{c}} / \mathrm{dm}^{3} ; \mathrm{CTC}-11.23 \mathrm{cmol}_{\mathrm{c}} / \mathrm{dm}^{3}$; $\mathrm{V}(\%)$ - 64.4; P - $68 \mathrm{cmol}_{\mathrm{c}} / \mathrm{dm}^{3}$ and $\mathrm{K}^{+}-142 \mathrm{cmol}_{\mathrm{c}} / \mathrm{dm}^{3}$.

The experiment was carried out in a completely randomized design with three treatments (Brachiaria brizantha var. Marandu, Xaraés and Piatã) and three replications. The experiment was planted in $4 \mathrm{~m}^{2}(2 \mathrm{~m} \times 2 \mathrm{~m})$ plots, spaced $1 \mathrm{~m}$ between plots. The cultivars were sown in a spacing of $10 \mathrm{~cm}$ between rows and $5 \mathrm{~cm}$ between plants. According to the result of the soil analyses, $20 \mathrm{~kg} / \mathrm{ha}$ of $\mathrm{P}_{2} \mathrm{O}_{5}$ as simple superphosphate were applied in the row of planting. Nitrogen and potassium fertilizers [ $(100 \mathrm{~kg} \mathrm{~N} / \mathrm{ha}$ (urea) and $80 \mathrm{~kg} \mathrm{~K}_{2} \mathrm{O} / \mathrm{ha}(\mathrm{KCl})$ ] were applied as cover after the complete establishment of the plants. After the harvests, maintenance fertilizations were done with $50 \mathrm{~kg} / \mathrm{ha} \mathrm{N}$ (urea) and $30 \mathrm{~kg} / \mathrm{ha} \mathrm{K}_{2} \mathrm{O}(\mathrm{KCl})$.

During the experimental period, seven harvests were conducted per plot: five during the rainy season (every 45 days) and two in the dry season (until the end of the dry period of the year). Plants of B. brizantha were cut at $20 \mathrm{~cm}$ from the soil level.

Immediately after each harvest, the forage was weighed to obtain green matter yield (GM). Samples were separated into leaf, stems + sheath and dead matter and were dried in a forced-ventilation oven at $55{ }^{\circ} \mathrm{C}$ until constant weight to estimate total dry matter yield (TDM), stem dry matter yield (SDM), leaf dry matter yield (LDM) and dead dry matter yield (DDM).

To estimate the coefficient of repeatability of each character evaluated, four methods were used: analyses of variance, analyses of principal components based on the phenotypic variance and covariance matrices and analyses of principal components based on interclass correlation matrix as described by Cruz et al. (2004).

To estimate the coefficient of repeatability by the method of variance analysis, the statistical model with two factors of variation was used:

$$
Y_{i j}=\mu+g_{i}+a_{i j}+e_{i j}
$$

in which $\mu=$ overall mean; $g_{i}=$ random effect of the i-th cultivar under the influence of the permanent environment; $a_{i j}=$ fixed effect of the temporary environment associated with the $\mathrm{j}$-th measure on the $\mathrm{i}$-th cultivar; $e_{i j}=$ temporary environmental effect associated with the $\mathrm{j}$-th measurement on the i-th genotype.

For this model, the coefficient of repeatability was estimated by:

$$
r=\frac{\operatorname{Cov}\left(y_{i j}, Y_{i^{\prime} j}\right)}{\sqrt{\operatorname{Var} Y_{i j} \cdot \operatorname{Var} Y_{i^{\prime} j}}}=\frac{\sigma_{g}^{2}+\sigma_{E s}^{2}}{\sigma_{g}^{2}+\sigma_{E s}^{2}+\sigma_{E g}^{2}}
$$

in which $\sigma_{g}^{2}$ is the covariance between repeated measurements in each cultivar; $\sigma_{E S}^{2}$ is the variance of the permanent environment; $\sigma_{E g}^{2}$ is the variance of the general environment.

The coefficient of repeatability by the analyses of the principal component analyses was estimated based on the matrix of correlations and matrices of phenotypic variance and covariances. The method of correlation matrix was proposed by Abeywardena (1972) and is based on obtaining a correlation matrix among the repeated measures and posterior estimate of the normalized eigenvalues and eigenvectors. Among the estimated eigenvectors, those with elements with the same signs and similar magnitudes are identified, since they express better the tendency of the cultivars to maintain their relative positions in the various periods of time. The coefficient of repeatability (r) was estimated by:

$$
r=\frac{\hat{\lambda_{1}}-1}{\eta-1}
$$

in which $\lambda_{1}$ is the eigenvalue of the correlation matrix associated with the eigenvector whose elements have the same sign and similar magnitude and $\eta$ is the number of measures.

The coefficient of repeatability ( $\mathrm{r}$ ) by the method based on the phenotypic variance and covariance matrix was obtained by: 


$$
r=\hat{\rho} \frac{\hat{\lambda}_{1}-\sigma_{Y}^{2}}{\sigma_{Y}^{2}(\eta-1)}
$$

in which $\hat{\lambda}_{1}$ is the eigenvalue of phenotypic variance and covariance matrix associated with the eigenvector whose elements have the same sign and similar magnitude, $\sigma^{2} Y=\sigma_{g}^{2}+\sigma_{e}^{2}$ is the variance of the character $Y$, in which $\sigma_{g}^{2}$ is the covariance between repeated measurements in each cultivar; and $\sigma_{e}^{2}$ is the variance of the environment.

The method of structural analyses was based only on the interclass correlations (r) and was estimated by:

$$
r=\frac{\hat{\alpha}^{\prime} R \hat{\alpha}-1}{\eta-1}
$$

in which, $\hat{\alpha}^{\prime} \mathrm{R} \hat{\alpha}=\lambda_{1}$ eigenvalue of the interclass correlation matrix associated with the eigenvector whose elements have the same sign and similar magnitude and $\hat{\alpha}^{\prime}$ is the eigenvector associated to $\lambda_{1}$, so that $\hat{\alpha}^{\prime} \hat{\alpha}=1$.

For each characteristic, the minimum number of measures necessary (n) to obtain efficiency in the selection process, based on pre-determined determination coefficients - $\mathrm{R}^{2}(80,85,90,95$ and 99\%), was estimated by:

$$
\eta_{o}=\frac{R^{2}(1-r)}{\left(1-R^{2}\right) r}
$$

The phenotypic stability of the characters was evaluated using the principal components methods obtained from the interclass correlation matrix for the successive measures, considering $2,3, \ldots$ until all $\mathrm{n}$ evaluations were done. Therefore, $\mathrm{n}-1$ analyses were done on two successive measures; $n-2$ analyses were done on three successive evaluations until reaching six measures (Martuscello et al., 2007).

All analyses were done with use of the computer software GENES (Aplicativo Computacional em Genética e Estatística Experimental, 2006) in the "Biometria" section.

\section{Results and Discussion}

For the $B$. brizantha cultivars, it was observed that the repeatability coefficients estimates (r) varied from 0.009 to 0.837 (Table 1). Highest values were recorded for stem dry matter (method of principal components: covariance) and the lowest values for dead dry matter (method of analyses of variance). Stem accumulation is fundamental in the choice of forage, since higher stem dry matter values indicate lower quality forage, since in the rumen, the stem presents less digestibility than the leaves. Forages that tend to elongate and accumulate stems along the seasons should be avoided over the others, and in this case, more value should be given to those that present higher production and repeatability of leaf dry matter. The higher values of repeatability for stem dry matter indicate that the cultivar with higher stem accumulation tends to present this characteristic repeatedly, which makes its choice unviable in relation to the others. Thus, selection based on leaf dry matter tends to make the process of breeding more efficient, especially in the last phase, where the evaluation of animal weight gain is the main indicator of the potential use of the plant.

The coefficients of repeatability for leaf dry matter yield for all methods used may be considered from medium to high (Table 1), since they varied from 0.411 (method of analyses of variance) to 0.706 (method of principal components: correlation). It is noteworthy that for this characteristic, the values of repeatability indicate the confidence in the identification of the best cultivar, considering the seven evaluations.

The determination coefficients $\left(\mathrm{R}^{2}\right)$ varied from 65.44 to $97.30 \%$ and were classified as medium to high for all the methods used to estimate the repeatability coefficients, with the exception of the characteristic dead dry matter yield (Table 1). As the coefficient of determination expresses the accuracy in the prediction of the real value of an individual, the confidence in the selection of the best cultivar of $B$. brizantha, based on the phenotypic value of SDM, will be $97.30 \%$ (method of the principal components: covariance); therefore, it was clear that the seven harvests were sufficient to reach high confidence in the prediction of the performance of the different cultivars.

Dead matter production was the characteristic that presented the least repeatability, regardless of the method used to estimate the coefficient (Table 1). In general, the production of dead matter is not a characteristic used in the selection of forages, but assumes an important role when analyzed in relation to animal nutrition, since cultivars that

Table 1 - Estimates of repeatability and determination coefficients (in brackets) of yield characteristics of Brachiaria brizantha cultivars evaluated by four methods of analysis

\begin{tabular}{lcccc}
\hline \multirow{2}{*}{ Method } & \multicolumn{3}{c}{ Characteristic } \\
\cline { 2 - 5 } & Total dry matter & Leaf dry matter & Stem dry matter & Dead dry matter \\
\hline Analyses of variance & $0.212(65.44)$ & $0.411(83.01)$ & $0.309(75.83)$ & $0.009(5.92)$ \\
Principal components (covariance) & $0.703(94.04)$ & $0.600(91.31)$ & $0.837(97.30)$ & $0.789(96.33)$ \\
Principal components (correlation) & $0.605(91.49)$ & $0.706(94.33)$ & $0.742(95.25)$ & $0.514(88.09)$ \\
Structural analyses (correlation) & $0.166(65.44)$ & $0.678(93.69)$ & $0.309(75.83)$ & $0.0(0.0)$ \\
\hline
\end{tabular}


tend to accumulate dead matter have less nutritional value. Even so, the accumulation of dead matter has a direct effect on pasture management, and management techniques that minimize the accumulation of dead matter should be prioritized. So, according to the results of repeatability, it may be inferred that the same management used for the different $B$. brizantha cultivars may influence the accumulation of dead matter.

It was verified that the repeatability coefficient estimates obtained for the four characteristics evaluated by the analyses of variance method were almost always lower than the estimates obtained by the other methods. It was also observed that by the method of principal components (based on the covariance matrix) these estimates were almost always greater than the other methods. Yet, for all characteristics evaluated, the estimates obtained by the four methods used demonstrate accuracy in the measures and high regularity in the superiority of the individuals. Martuscello et al. (2007) reported greater superiority of the principal components method (based on the covariance matrix) in the evaluation of repeatability of agronomic characters in $P$. maximum. Also, Cargnelutti Filho et al. (2004), evaluating $P$. maximum cultivars with or without light restriction, reported greater repeatability of yield characteristics when the principal components method was used (based on the covariance matrix).

According to Abeywardena (1972), the principal components method estimates more efficiently the repeatability coefficient in situations where genotypes present cyclic behavior in relation to the character studied, because it is based on the covariance matrix between genotypes obtained in each pair of measures. According to Cruz et al. (2004), the analyses of variance method may, in some cases, underestimate the coefficient of repeatability. In general, according to Martuscello et al. (2007) the differences between the estimates of the repeatability coefficients by the four methods indicate the need to use the various methods available to obtain a precise interval, in which the real value for this parameter will be found.

Concerning the simulation of the number of harvests necessary to obtain different coefficients of determination of the characteristics evaluated by the four methods used (Table 2), as precision increased in relation to the prediction of the real value of the evaluations, by all methods used, a considerable increase in the number of measures for all characteristics was implied. These data suggest that the attempt to increase precision above 95\% would demand an exaggerated increase in the number of measures, which, in turn, would add very little in terms of precision; so its use is unjustified, which may be indicative that the number of cuts used for choosing the best cultivar may have been sufficient.

In the selection of $P$. maximum hybrids, Resende et al. (2004) obtained $80 \%$ precision for leaf dry matter, with four years of evaluation with harvests, but with small increases in the efficiency of selection after three years of evaluation (15 harvests). For B. brizantha, Basso et al. (2009) obtained $80 \%$ precision for this characteristic with six to 14 harvests, according to the genotypes evaluated in different localities.

The number of harvests necessary to characterize the yields of total, leaf, stem and dead dry matter with $80 \%$ probability by the method of principal components (based on the covariance matrix) was $2,3,1$ and 1 , respectively (Table 2). This indicates that it is not necessary to perform seven harvests for these characteristics, since only four (for the method that estimates the greater number of measures) result in a good confidence, reducing, therefore, labor and time. In general, by both principal component methods, the number of harvests done (seven) was sufficient to obtain a confidence of $80 \%$ for all the characteristics evaluated.

Table 2 - Number of measures of yield characteristics of Brachiaria brizantha cultivars, associated with different determination coefficients of the genotypic value $\left(\mathrm{R}^{2}\right)$, by four methods of estimation of the repeatability coefficient

\begin{tabular}{llccc}
\hline $\mathrm{R}^{2}(\%)$ & Variance & $\begin{array}{c}\text { Principal } \\
\text { components } \\
\text { analyses }\end{array}$ & $\begin{array}{c}\text { Principal } \\
\text { components } \\
\text { (correlation) }\end{array}$ & $\begin{array}{c}\text { Structural } \\
\text { analyses } \\
\text { (correlation) }\end{array}$ \\
\hline
\end{tabular}

Total dry matter

\begin{tabular}{ccccc}
0.80 & 15 & 2 & 3 & 20 \\
0.85 & 21 & 2 & 4 & 28 \\
0.90 & 33 & 4 & 6 & 45 \\
0.95 & 70 & 8 & 12 & 96 \\
0.99 & 366 & 42 & 64 & 498 \\
& & Leaf dry matter & & \\
0.80 & 6 & 3 & 2 & 2 \\
0.85 & 8 & 4 & 2 & 3 \\
0.90 & 13 & 6 & 4 & 4 \\
0.95 & 27 & 13 & 8 & 9 \\
0.99 & 142 & 66 & 41 & 47 \\
& & Stem dry matter & & \\
0.80 & 9 & 1 & 1 & 8 \\
0.85 & 13 & 1 & 2 & 11 \\
0.90 & 21 & 2 & 3 & 18 \\
0.95 & 42 & 4 & 7 & 37 \\
0.99 & 221 & 19 & 34 & 195 \\
& & Dead dry matter & & \\
0.80 & 445 & 1 & 4 & 11 \\
0.85 & 630 & 1 & 5 & 21 \\
0.90 & 1000 & 1 & 5 & 33 \\
0.95 & 2113 & 5 & 18 & 45 \\
0.99 & 11010 & 26 & 93 & 295 \\
\hline
\end{tabular}

R. Bras. Zootec., v.42, n.1, p.30-35, 2013 
Regarding the evaluation of ecosystems lacking information on the best cultivar to be utilized, such as the Brazilian agreste region, the lower the number of cuts, the faster will be the recommendation of the best cultivar, which can advance the process of gain in animal production in this region.

To obtain higher confidence, the coefficient of determination of $90 \%$ may be used in the selection of the best genotypes for all the evaluated characteristics, and in this case, a maximum of 33 harvests are necessary according to the methodology to be used to obtain higher accuracy, with the exception of dead dry matter yield. However, it is noteworthy that the accumulation of dead matter is not a desirable characteristic in the choice of forages for cultivation, as cited earlier, since this characteristic correlates negatively with animal production and, in this case, if selection were done for dead matter production, 1000 harvests would be necessary (method of analyses of variance).

Concerning phenotypic stabilization for the characteristics of total, leaf, stem and dead dry matter for the seven harvests evaluated, for the variable total dry matter, the highest coefficient of repeatability was obtained when harvests two and three, harvests two, three and four, and harvests six and seven were correlated, and the lowest values when harvests four and five and the first three harvests were correlated (Table 3). The low correlation between the harvests four and five for total and leaf dry matter (Table 3) and stem dry matter (Table 4) may be explained by the harvest period, since the fourth harvest occurred at the end of the dry season. It is known that changes occur in the proportion of the botanical components of the plant along with the seasons of the year. The use of the stabilized genotypes is very important when obtaining repeatability estimates. In some cases, there is the possibility that the character is governed by a group of distinct genes that may be more or less active according to the stage of development of the individuals. In some cases, repeatability may be underestimated by the evaluations being done at an early stage, where the genetic potential of the plant is not completely expressed, or by the evaluations done at a late stage where the forage already presents a certain degree of senescence. Thus, if the genotype over which the measures are taken is not stabilized, the variation within the individuals will include a considerable part of the variance of the genotype $\times$ temporary environment interaction and the increase in the number of measures aiming at reducing the variation within individuals may not be advantageous, since the additional variance may be sufficient to neutralize the reduction of the component.

The correlation among harvests and the stabilization of the genotype for leaf dry matter (Table 3 ) and stem dry matter (Table 4) probably suffered direct effect from the flowering period of each cultivar, there is higher accumulation of

Table 3 - Estimate of the number of measures and determination coefficients of the genotypic value $\left(\mathrm{R}^{2}\right)$ necessary for phenotypic stability by the principal components method from the correlation matrix for total and leaf dry matter yields in cultivars of Brachiaria brizantha in seven consecutive harvests

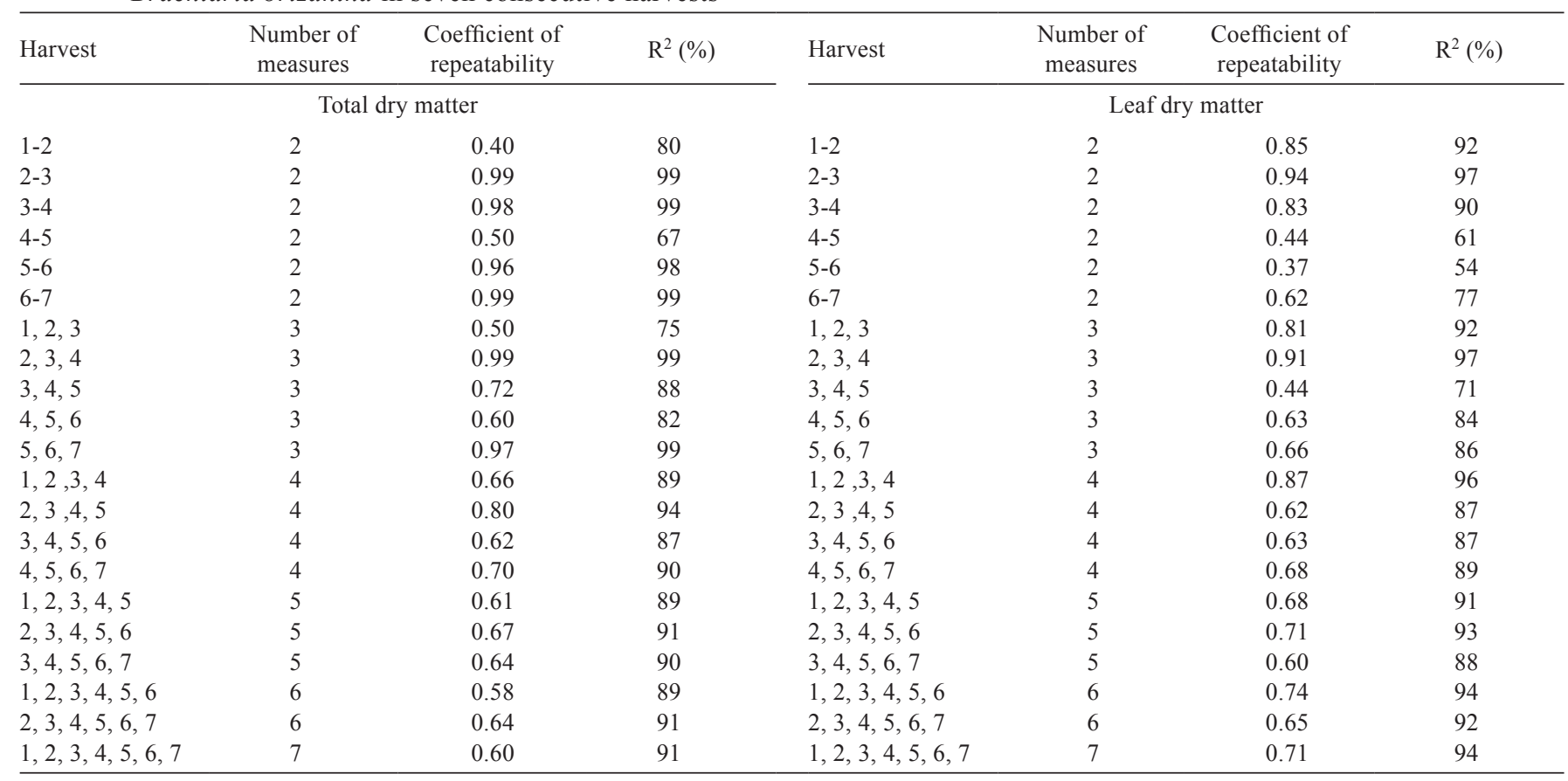


Table 4 - Estimate of the number of measures and determination coefficients of the genotypic value $\left(\mathrm{R}^{2}\right)$ necessary for phenotypic stability by the principal components method from the correlation matrix for stem and dead dry matter in cultivars of Brachiaria brizantha in seven harvests

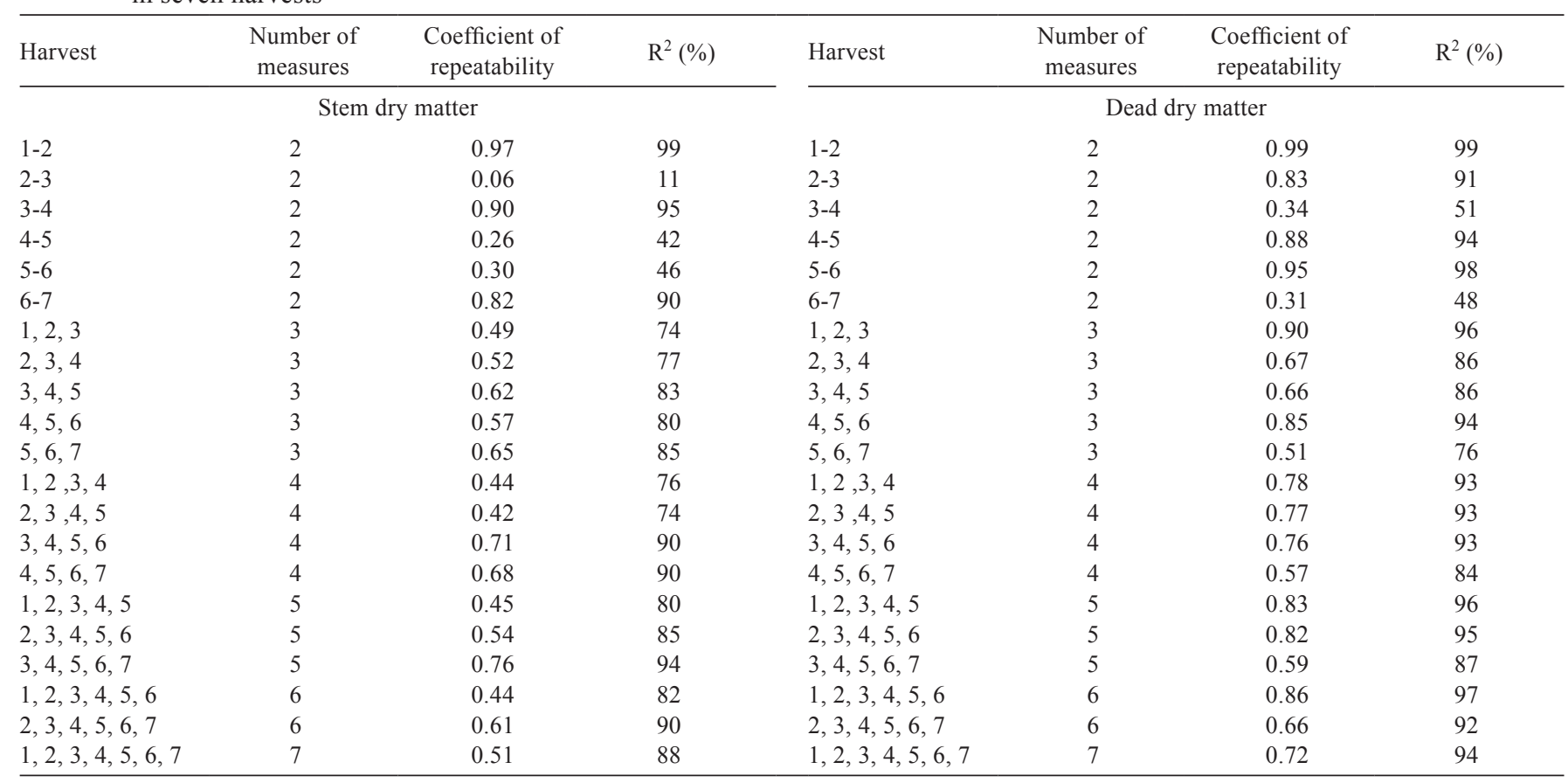

stems at flowering, with a consequent direct effect of this accumulation on leaf dry matter yield. This may be rectified by the low correlation between harvests 5 and 6 for both characteristics, since the plants were flowering before harvest 6 .

\section{Conclusions}

For a reliable selection ( $90 \%$ probability) based on total, leaf, stem and dead dry matter of Brachiaria brizantha cultivars in the region of the agreste of Alagoas state, Brazil, at least four harvests are necessary. However, it is necessary to use the various methods of analyses available to obtain a precise interval for each parameter in order to find the real value with greater probability. Moreover, considering the methods evaluated in this experiment would be interesting based on the method of principal components (based on the covariance matrix).

\section{References}

ABEYWARDENA, V. An application of principal component analysis in genetics. Journal of Genetics, v.16, p.27-51, 1972.

AGUIAR, P.A.A.; MENEZES, E.A.; SANTOS, M.X. Breve caracterização da Região Nordeste e principais sistemas produtivos da região semi-árida. Petrolina: Embrapa. CPATSA, 1981. 17p.

BASSO, K.C.; RESENDE, R.M.S.; VALLE, C.B. et al. Avaliação de acessos de Brachiaria brizantha Stapf e estimativas de parâmetros genéticos para caracteres agronômicos. Acta Scientiarum. Agronomy, v.31, p.17-22, 2009.

CARGNELUTTI FILHO, A.; CASTILHO, Z.M.S.; STORCK, L. et al. Análise de repetibilidade de caracteres forrageiros de genótipos de Panicum maximum, avaliados com e sem restrição solar. Ciência Rural, v.34, p.723-729, 2004.

CRUZ, C.D. REGAZZI, A.J.; CARNEIRO, P.C.S. Modelos biométricos aplicados ao melhoramento genético. v.1. 3.ed. Viçosa, MG: UFV, 2004. 480p.

EMPRESA BRASILEIRA DE PESQUISA AGROPECUÁRIA - EMBRAPA. Centro nacional de pesquisa de solos. Sistema brasileiro de classificação de solos. Rio de Janeiro: EMBRAPA Solos, 1999. 412p.

FALCONER, D.S.; MACKAY, T.F.C. Introduction to quantitative genetics. 4.ed. Burnt Mill, Harlow, United Kingdom: Longman Scientific \& Technical, 1996. 464p.

LUSH, J.L. Melhoramento dos animais domésticos. Tradução de CARNEIRO, G.G.; MEMORIA, J.M.P.; DRUNMOND, G. Rio de Janeiro: CEDEGRA, 1964. 566p.

MARTUSCELLO, J.A.; JANK, L.; FONSECA, D.M. et al. Repetibilidade de caracteres agronômicos em Panicum maximum Jacq. Revista Brasileira de Zootecnia, v.36, p.1975-1981, 2007.

RESENDE, R.M.S.; JANK, L.; VALLE, C.B. et al. Biometrical analysis and selection of tetraploid progenies of Panicum maximum Jacq. using mixed model methodology. Pesquisa Agropecuária Brasileira, v.39, p.335-341, 2004.

TURNER, H.N.; YOUNG, S.Y. Quantitative genetics in sheep breeding. Ithaca: Cornell University Press, 1969. 331p. 